\title{
Typology and Feature Checking of Wh-Questions
}

\author{
Ma Daoshan* \\ English Department, School of Foreign Languages, Tianjin Polytechnic University, 399\#, Binshuixidao, Xiqing Area,Tianjin, China, \\ 300387
}

A B S T R A C T

\begin{abstract}
From the perspective of the syntactic behavior of wh-questions, natural languages can be classified into four types: Null Spec Language, Single Filled Spec Language, Multiply Filled Spec Language and Non-Multiply Filled Spec Language. Data were collected according to the relevance to the present research from each representative of the four types of languages, namely, Chinese, English, Bulgarian and Czech. Some of the data in the thesis were taken from the previous literature. Others were from self-introspection. The collected data were analyzed from the point of typology and feature checking. Feature checking in wh-questions of these four types of languages seem to be operated quite differently. Pied-piping of the formal features of the wh-words or wh-phrases occur in English, Bulgarian and Czech but not in Chinese. However, feature movement in wh-questions of these four types of languages is universal. This finding proves Chomsky's biological linguistic belief that language is mainly an optimal solution to conditions it must satisfy.
\end{abstract}

A R T I C L E I N F O

Paper type:
Empirical Research
Article history:
Received 27 November 2017
Revised 14 March 2018
Accepted 16 March 2018
Keywords:
- feature checking
- $\quad$ wh-feature
- $\quad$ moature

\section{Introduction}

The syntactic behavior of wh-questions in the world can be roughly classified into 4 types (Ma, 2001; 2015; 2016a; 2016b). The first type of natural language is null filled spec language, in which the spec of CP is filled with no wh-word. The second type of language is singly filled spec language, in which the spec of CP is filled with only 1 wh-word. The third type of language is multiply filled spec language, in which the spec of CP is filled with more than one wh-words. The forth type is the non-multiply filled spec language in which one whword is in the spec CP and the other wh-words move to spec IP. Chinese is the first type of language in which the wh-word does not have to move to the spec $\mathrm{CP}$ for feature checking requirement, and instead the wh-feature of the wh-word moves to spec CP for feature checking of the weak specifier feature of the head. English is the second type of language in which one and only one wh-word moves to the spec $\mathrm{CP}$ for feature checking requirement, and the wh-word moves to spec $\mathrm{CP}$ for feature checking of the strong specifier feature of the head. Bulgarian is the third type of language, in which all wh-words in the sentence must move to spec CP for feature checking requirement, and all the wh-words form a mutual wh-operator and move to spec $\mathrm{CP}$ for feature checking of the strong specifier feature of the head. Czech is the forth type of language in which one wh-word can move to spec $\mathrm{CP}$ and at most another wh-word can be attached to the moved wh-word in spec $\mathrm{CP}$ and other wh-word or wh-words move to spec IP.

In this paper we will mainly deal with wh-feature checking of wh-questions in the different type of languages in which wh-word behaves differently in reference to different types of languages.

\footnotetext{
*Email Addresses: madaos@tom.com 


\section{Result and Discussion}

\subsection{Null Spec Language}

Chinese is the first type of language which does not require any wh-word to move to the spec CP position for feature checking. It belongs to the so-called null spec type of language (Ma, 2001; 2015; 2016a; 2016b). As in recent literature (Ma, 2016b; 2017a), it shows that either unselective binding (Tsai, 1994; Shi, 1994; Wu, 1999) or LF-movement (Huang, 1982a; 1982b) fails to work in the interpretation of wh-questions in the bamboo slips of Tao Te Ching (Ma, 2017a; 2017b). In the following section the author tries to resort to the Interrogative Feature Attraction Hypothesis (Ma, 2004a; 2004b; 2006a; 2006b; 2008; 2014; 2017c; 2017d) for the explanation of wh-questions in Chinese.

(1) Interrogative Feature Attraction Hypothesis

In null specifier type of languages, the interrogative head with weak interrogative feature, located at the end of the interrogative sentence, attached to by the affix question particle "ne"/ "ma" or the rising tone Q in modern Chinese, and "ye" / "zai" / "hu" or the rising tone Q in archaic Chinese, attracts the interrogative feature of the wh-word or the interrogative construction to move to spec CP position so that the interrogative feature is checked and thus the sentences can be interpreted as interrogative sentences.

In (2), as you can see, the Chinese wh-question is different from other types of languages in that the whword does not move to spec CP and stays in-situ.

(2) ni xihuan shenme ke?

You like what course

"Which course do you like?"

Following (1), in (2) the wh-word is a modifier of the DP "shenme ke" ("which course" in English) and the movement of the feature of the wh-word out of the DP violates the complex NP constraint. "shenme ke"

(3) Complex NP Constraint

Wh-word cannot be extracted out of the complex NP.

Therefore in (2), the wh-feature of the whole wh-phrase, that is, the DP "shenme ke" moves to the spec of CP to satisfy the wh-criterion.

(4) Wh-criterion

All [+wh] complementizers must contain a [+wh] constituent.

As it is shown in (2), in spec CP there is no [+wh] constituent. As the specifier [+wh] feature of the head $\mathrm{C}$ in Chinese wh-questions is weak, no wh-word or wh-phrase is attracted to move to the spec $\mathrm{CP}$ for [+wh] feature checking. Therefore (4) may be revised as (5):

(5) Wh-criterion

All [+wh] complementizer or complementizer phrase must contain a [+wh] feature.

In light of (5), (2) can be explained in (6).

(6) $[\mathrm{CP}[+\mathrm{wh}][\mathrm{IP}$ ni xihuan [DP shenme ke]

In (6), the wh-feature of the DP "shenme ke" is attracted by the weak specifier feature of the head C and moves to spec CP to check the specifier feature of the head, and the wh-feature of the DP "shenme ke" agrees with the weak specifier feature of the head $\mathrm{C}$, the weak specifier feature of the head $\mathrm{C}$ is checked and thus deleted because the weak specifier feature of the head $\mathrm{C}$ is uninterpretable. The derivation converges and the sentence is grammatical. This process of wh-feature checking can be illustrated as in (7): 
(7)

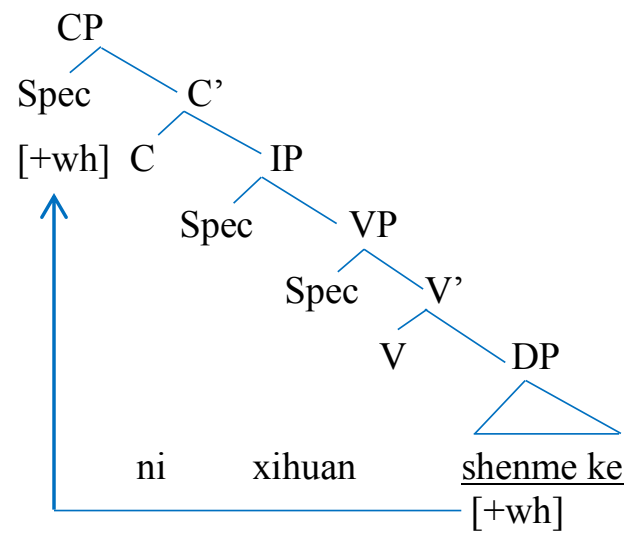

In Chinese, however, sentence (2) can also be uttered with a question particle at the end of the sentence. This question particle is neither a clause typer proposed by Cheng (1997) nor a question operator advocated by Aoun (1993a) and Aoun (1993b), as the use of the particle is not obligatory and thus the particle is not interrogative in nature (Ma, 2004a; 2004b).

(8) ni xihuan shenme ke ne?

You like what course Part.

"Which course do you like?"

The question particle "ne" at the end of the sentence does not carry any lexical meaning of interrogation; therefore it cannot be an interrogative head. This understanding of the syntactic behavior of particle as non-head also follows Kayne (2015) and Tang (2015). The wh-questions in the earliest found version of Tao Te Ching do not carry any question particles at the end of the sentences, and this also shows that question particles are not likely to be the heads of the sentence CP (Ma, 2017a). Question particles are affixes at the sentential level. They are affixes attached and adjoined to the head of the CP in Chinese who-questions (Ma, 2017a). The question particle "ne" is a phonological constituent but not a syntactic constituent (Ma, 2017a).

(9)

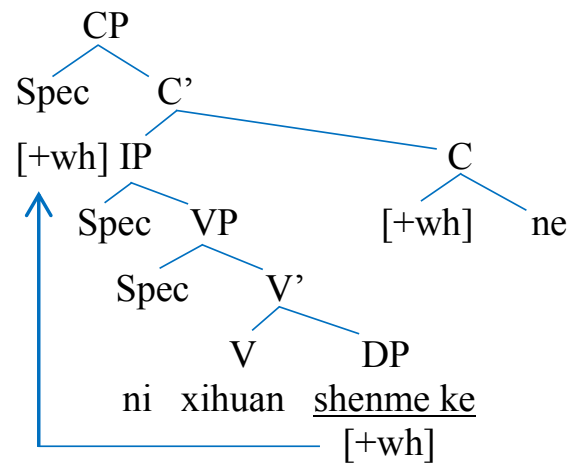

Sentence (9) is the tree diagram of (8). As is shown in (9), the [+wh] specifier feature of C is weak and cannot attract the whole wh-phrase "shenme ke" to move to the spec CP position for checking requirement. This weak [+wh] specifier feature of $\mathrm{C}$ can only attract the [+wh] feature of the wh-phrase "shenme ke" to move to the spec CP position. After the feature attraction, the [+wh] feature of the wh-phrase "shenme ke"moved to the spec $\mathrm{CP}$ position agrees with the weak [+wh] specifier feature of $\mathrm{C}$. And therefore the weak [+wh] specifier feature of $C$ is checked and as this [+wh] specifier feature of $C$ is an uninterpretable feature, after it is checked, it is erased immediately. And then after the great spell-out, in PF or in syntax phonology interface, the question particle "ne" is adjoined to the head C position at the end of the sentence. The derivation converges and the sentence is grammatical. The question particle "ne" is phonologically derived rather than syntactically derived. It is produced after the spellout of the derivation in phonological form.

In sentence (10), the wh-feature of the first wh-word "shei" moves to spec CP for feature checking of the weak specifier [+wh] feature requirement of the head. This weak [+wh] specifier feature of $\mathrm{C}$ can only attract 
the [+wh] feature of the wh-word "shei" to move to the spec CP position. After the feature attraction, the [+wh] feature of the wh-word "shei" moved to the spec CP position agrees with the weak [+wh] specifier feature of C. And therefore the weak [+wh] specifier feature of $\mathrm{C}$ is checked and as this [+wh] specifier feature of $\mathrm{C}$ is an uninterpretable feature, after it is checked, it is erased immediately. And then after the great spell-out, in PF or in syntax phonology interface, the question particle "ne" is adjoined to the head C position at the end of the sentence. The derivation converges and the sentence is grammatical. The question particle "ne" is phonologically derived rather than syntactically derived. It is produced after the spellout of the derivation in phonological form. (11) is the syntactic representation of (10).

(10) shei xihuan shenme ke ne?

Who like what course Part.

"Who likes which course?"

(11) $\left[\mathrm{CP}[+\mathrm{wh}]_{\mathrm{i}}\left[\mathrm{IP}\right.\right.$ shei $\mathrm{i}_{\mathrm{i}}$ xihuan shenme ke ne?]]

In (10), as the wh-word "shei" carries interrogative [ + wh] feature, the $[+w h]$ feature is optimally moved to the spec CP position. In such a case, if we move the [+wh] feature of the wh-phrase "shenme ke" to the spec CP position, the movement is not allowed because this movement violates Wh-island constraint. The first wh-word with [+wh] feature constitutes an island for the movement of the feature of the wh-phrase.

(12) Wh-island Constraint

The feature of a wh-phrase cannot be extracted out of the wh-island.

But sentence (10) can also be interpreted as "shenme ke shei xihuan" (literally "Which course does who like" in English) in which the wh-phrase occupies the wide scope in the sentence. This interpretation can take place only when the wh-word "shei" is used as an indefinite in the sentence without any [+wh] feature and so it is not an island for the feature of the wh-phrase. (13) is the representation of (10).

(13) $\left[\mathrm{cP}[+w h]_{i}\left[\text { IP } \text { shei } \mathrm{j}_{\mathrm{j}} \text { xihuan [DP shenme ke }\right]_{\mathrm{i}}\right.$ ne?]]

In (13), the weak [+wh] specifier feature of C can only attract the [+wh] feature of the wh-phrase "shenme ke" to move to the spec CP position. After the feature attraction, the $[+w h]$ feature of the wh-phrase "shenme ke" moved to the spec $\mathrm{CP}$ position agrees with the weak [+wh] specifier feature of $\mathrm{C}$. And therefore the weak [+wh] specifier feature of $\mathrm{C}$ is checked and as this [+wh] specifier feature of $\mathrm{C}$ is an uninterpretable feature, after it is checked, it is erased immediately. And then after the great spell-out, in PF or in syntax phonology interface, the question particle "ne" is adjoined to the head $\mathrm{C}$ position at the end of the sentence. The derivation converges and the sentence is grammatical.

Hereinafter we therefore propose the Wh-feature Attraction Principle as represented in (14). This principle also follows Chomsky (2008).

(14) Wh-feature Attraction Principle

The wh-feature of a wh-word or a wh-phrase must be attracted to spec CP in wh-questions for wh-feature checking requirement.

The wh-feature attraction is triggered by the principle of greed as represented in (15). Only when the morphological feature of a cannot be otherwise satisfied in the derivation can the principle of movement raise a.

(15) The Principle of Greed

Move raises a only if morphological properties of a itself would not otherwise be satisfied in the derivation (Chomsky, 2008).

The wh-feature attraction hypothesis also accords with the Last Resort schematized as in (16).

(16) Last Resort 
Movement of a targeting $\mathrm{K}$ is permitted only if the operation is morphologically driven, by the need to check some feature (Chomsky, 2008).

\subsection{Single Filled Spec Language}

English is a single filled spec language in which only one wh-word is allowed to move into spec $\mathrm{CP}$ for feature checking in the wh-questions (Ma, 2001).

The English counterpart of (2) is (17).

(17) Which course do you like?

In the English sentence (17), according to the wh-feature attraction principle of (14), why not just Move F alone ? Move F in (18) alone could satisfy (14) as well as the Principle of Greed as illustrated in (15) and Last Resort as in (16).

As Chomsky (2008) says, "The minimal operation, then, should raise just the feature F.", that is why in section 1 we propose that Wh-feature Attraction Principle should be a universal principle.

(18) Move $\mathrm{F}$

$\mathrm{K}=\{\gamma,\{\alpha, \beta\}\}$, where $\alpha, \beta$ are features of syntactic objects already formed.

Chomsky (2008) answers why $\mathrm{F}$ does not raise alone to form $\{\gamma,\{\mathrm{F}, \mathrm{K}\}\}$ when $\mathrm{F}$ is raised to target $\mathrm{K}$. Why is it not the case that only the formal feature of the wh-word involved in feature checking raise to relevant spec $\mathrm{CP}$ position. The explanation lies in the following economy principle.

(19) Economy Principle

F carries along just enough material for convergence.

In Chinese, the operation Move tries to attract just the wh-feature. In the English sentence (17), an extra baggage is required to move along with the wh-feature for convergence which involves a kind of generalized pied-piping, according to Chomsky (2008). Optimally speaking, bare output conditions should determine just what is piedpiped or carried along when $\mathrm{F}$ is moved. Chomsky (2008) thinks that it is the properties of phonological component that require such pied-piping. Thus in (17), Move F carries along the morphological feature of the wh-word "which" and leaving the residue "course" behind. This too crashes at PF. The wh-word "which" cannot raise because it is not a syntactic constituent which is subject to movement. In fact, the smallest element that can be moved as a category in the sentence of (17), is the DP "which course". According to Chomsky (2008), here as far as the computational procedure is concerned, it is only the feature [+wh] that is raising, the rest is carried along by virtue of the economy principle of (19). This also shows that Move F is universal as it accords with economy condition while pied-piping of the extra baggage is conditional. As (17) illustrates, Move F in English automatically carries along FF(LI), the set of formal features of the lexical item. Therefore, in English Move $\mathrm{F}$ must follow (20), where $\mathrm{FF}(\mathrm{F})$ is $\mathrm{FF}(\mathrm{LI}), \mathrm{F}$ a feature of the lexical item LI, according to Chomsky (2008).

(20) Move F “carries along” FF(F).

In (17), the operation Move raises $\mathrm{F}$ and automatically raises $\mathrm{FF}(\mathrm{F})$ as well, carrying along the phrase "which course" containing F only when the movement is overt, otherwise the derivation will crash. In the Chinese sentence (2), the operation Move raises $F$ and does not automatically raise $F F(F)$ as well, carrying along the phrase "which course" containing F because the movement is covert, and according to Chomsky (2008), in covert movement, features raise alone. Thus the essence of Last Resort can also be captured as a property of the operation Move F.

(21) Last Resort as a property of the operation Move F

$\mathrm{F}$ is unchecked and enters into a checking relation with a sub label of $\mathrm{K}$ as a result of the operation. 
Chomsky (2008) further elaborates the theory of the operation Move. Move raises feature F to target K in $\Sigma$ only if (22) holds, with (23a) and (23b) as automatic consequences and (23c) a further consequence.

(22) Last Resort

a. $\mathrm{F}$ is an unchecked feature.

b. F enters into a checking relation with a salable of $\mathrm{K}$ as a result of the operation.

(23) Move F

a. $\mathrm{FF}(\mathrm{F})$ raises along with $\mathrm{F}$.

b. A category $\alpha$ containing $F$ moves along with $F$ only as required for convergence.

c. Covert operations are pure feature raising.

According to the theory of Move mentioned in (22) and (23), in (17) the [+wh] feature of the wh-phrase "which course" is an unchecked feature and thus this feature enters into a checking relation with a sublablel of K as a result of the operation. The [+wh] feature of the wh-phrase "which course" actually enters into a checking relation with the specifier [+wh] feature of the head C in CP. In the checking process, Move F automatically carries along the $\mathrm{FF}(\mathrm{F})$ formal feature of the lexical item the wh-phrase "which course". The category DP "which course" containing $\mathrm{F}$ the $[+$ wh] feature of the wh-phrase "which course" moves along with $\mathrm{F}$ only as required for convergence. The category DP "which course" containing F the [+wh] feature of the wh-phrase "which course" moves along with F into spec CP to check the specifier [+wh] feature of the head. And only when the category DP "which course" containing F the $[+w h]$ feature of the wh-phrase "which course" moves into spec $\mathrm{CP}$, the specifier [+wh] feature of the head can be checked. The $[+w h]$ feature of the category DP "which course" containing F the [+wh] feature of the wh-phrase "which course" agrees with the specifier [+wh] feature of the head and thus the specifier [+wh] feature of the head is checked. And as the specifier [+wh] feature of the head is uninterpretable, once it is checked it is erased and does not enter into LF. The derivation converges. In the Chinese sentence (2), however, only pure feature raising is required. That's why (2) abides by wh-feature attraction hypothesis. In Chinese the specifier [+wh] feature of the head is weak, the $F F(F)$ feature is not piedpiped. While in English the specifier [+wh] feature of the head is strong, the $\mathrm{FF}(\mathrm{F})$ feature of the category DP "which course" must be carried along with Move F. There are four types of features (Chomsky, 2008):

(24) a. categorical features

b. $\Phi$-features

c. Case features

d. strong $\mathrm{F}$, where $\mathrm{F}$ is categorical.

The structure of (17) can be illustrated by the representation of (25).

(25) [CP which course $\mathrm{i}_{i}$ [IP do you like $\left.\left.t_{i}\right]\right]$

The tree diagram of (17) is (26).

(26)

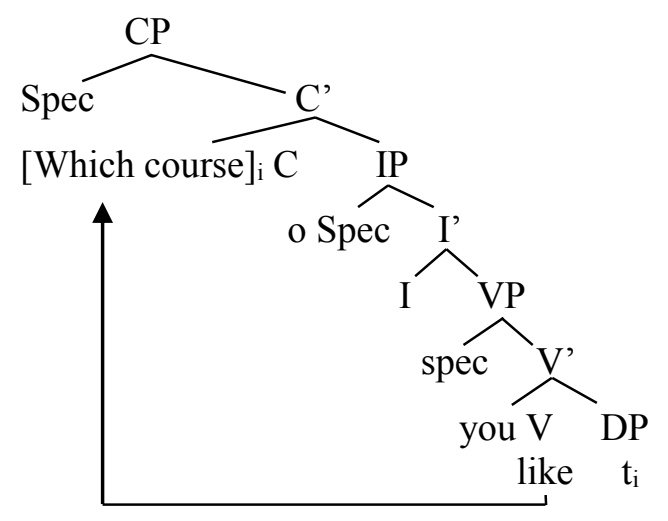


The English counterpart of (10) is (27), as is illustrated in (28).

(27) Who likes which course?

(28) $\left[\mathrm{CP}\left[+\mathrm{who}_{\mathrm{i}}\left[\mathrm{IP} \mathrm{t}_{\mathrm{i}}\right.\right.\right.$ likes which course?]]

According to the theory of Move represented in (22) and (23), in (28) the [+wh] feature of the wh-word "who" is an unchecked feature and thus this feature enters into a checking relation with a sublablel of $\mathrm{K}$ as a result of the operation. The [+wh] feature of the wh-word "who" actually enters into a checking relation with the specifier [+wh] feature of the head $\mathrm{C}$ in CP. In the checking process, Move F automatically carries along the FF(F) formal feature of the lexical item the wh-word "who". The category DP "who" containing F the [+wh] feature of the wh-word "who" moves along with F only as required for convergence. The category DP "who" containing F the [+wh] feature of the wh-word "who" moves along with F into spec CP to check the specifier [+wh] feature of the head. And only when the category DP "who" containing F the [+wh] feature of the wh-word "who" moves into spec CP, the specifier [+wh] feature of the head can be checked. The [+wh] feature of the category DP "who" containing F the [+wh] feature of the wh-word "who" agrees with the specifier [+wh] feature of the head and thus the specifier [+wh] feature of the head is checked. And as the specifier [+wh] feature of the head is uninterpretable, once it is checked it is erased and does not enter into LF. The derivation converges. The derivation follows Wh-feature Attraction Principle in (14).

In (28) the wh-word "who" takes a wide scope over the lower wh-phrase "which course". As the wh-word "who" carries interrogative [+wh] feature, the $[+w h]$ feature is optimally moved to the spec CP position, and according to the economy principle in (19) and move operation in (20), this movement of F carries along FF (LI). Thus the whole lexical item moves to the spec CP. In such a case, if we move the [+wh] feature of the whphrase "which course" to the spec CP position, the movement is not allowed because this movement violates Wh-island constraint in (12) repeated here in (29). The first wh-word with [+wh] feature constitutes an island for the movement of the feature of the wh-phrase "which course". The movement of the lexical item the whphrase "which course" illustrated in (30) violates (29) as this movement crosses over the wh-word "who". The wh-word "who" constitutes a wh-island for the pied-piped movement of the lexical item the wh-phrase "which course", when the wh-feature of the wh-phrase "which course" is raised to spec CP. The pied-piped movement of the wh-phrase "which course" is against the wh-island constraint, and thus the derivation crashes, and the sentence in (30) is ungrammatical. The representation is illustrated in (31).

(29) Wh-island Constraint

The feature of a wh-phrase cannot be extracted out of the wh-island.

(30) *Which course does who like?

(31) $*[\text { ср [+which course }]_{i}$ does [IP who like $t_{i}$ ?]

\subsection{Multiply Filled Spec Language}

Rudin (1988) assumes that in the wh-movement languages such as Bulgarian, Polish and Hungarian, all the whwords in the multiple wh-questions must be moved to the front of the sentences. She classifies languages of multiple wh-questions into 2 types: [+Multiply Filled Spec CP, +MFS] such as Bulgarian and Romanian languages and [-Multiply Filled Spec CP, -MFS] such as Polish, Czech and Croatian languages.

In Bulgarian language, all the wh-words must raise to the spec position of CP. In (32) Ackema \& Ad, (1998), the wh-word "kakva"("what" in English) in Bulgarian language must move to the front position of Spce $\mathrm{CP}$, and the verb "kupuva"("bought" in English) must be inverted. If the verb is not inverted, the sentence is ungrammatical. In Bulgarian, $\mathrm{C}$ in wh-question carries a very strong [+wh] feature, and this feature attracts the wh-feature of the wh-word to move to Spec CP position in the front of the sentence for [+wh] feature checking. As the [+wh] feature in $\mathrm{C}$ is too strong, the morphological feature of the wh-word moves along with the [+wh] feature. The $[+w h]$ feature in $C$ is in agreement with the $[+w h]$ feature of the wh-word. As a result, (32) is interpreted as a wh-question. 
(32) a. kakvo kupuva Ivan what bought Ivan "What did Ivan buy?"

b. *kakvo Ivan kupuva what Ivan bought

If a question is raised about Ivan, the object "koj" ("who" in English) in Bulgarian may violate wh-island condition and move all the way up to the initial position of Spec CP. What's more, the wh-word in spec CP position must abide by Superiority Condition and Economy Principle. The wh-word in subject position must always occur in front of the wh-word in object position, as is shown in (33). In Bulgarian, C in wh-question carries a very strong [+wh] feature, and this feature attracts the wh-features of all the wh-words to move to Spec $\mathrm{CP}$ position in the front of the sentence for $[+w h]$ feature checking. The wh-features of all the wh-words must be integrated as a wh-feature cluster. As the $[+w h]$ feature in $\mathrm{C}$ is too strong, the morphological features of the wh-words piped-pipe with the [+wh] feature cluster. The [+wh] feature in $\mathrm{C}$ is in agreement with the [+wh] feature cluster of all the wh-words. As a result, (33) is interpreted as a wh-question.

(33) koj kakvo kupuva

Who what bought

"Who bought what?"

Another difference is that when all the wh-words are moved to the front position of the wh-questions, no constituent should be inserted in between the wh-words, as in the examples of (34). In (34), C in wh-question carries a very strong [+wh] feature, and this feature attracts the wh-features of all the wh-words to move to Spec $\mathrm{CP}$ position in the front of the sentence for $\left[{ }^{+} \mathrm{wh}\right]$ feature checking. The wh-features of all the wh-words must be integrated into a wh-feature cluster. As the $[+w h]$ feature in $\mathrm{C}$ is too strong, the morphological features of the wh-words also form a morphological feature cluster and piped-pipe with the [+wh] feature cluster. The [+wh] feature in $\mathrm{C}$ is in agreement with the [+wh] feature cluster of all the wh-words. As a result, (34a) is interpreted as a wh-question. (34b) is ungrammatical because the [+wh] features of all the wh-words cannot be integrated into one $[+w h]$ feature cluster as there is a constituent "pruv" in between them which prevents the features of the two wh-words from forming a [+wh] feature cluster, and thus the $[+$ wh] feature in $\mathrm{C}$ cannot be checked and therefore the sentence cannot be interpreted as a wh-question.

(34) a. koj kakvo pruv kupuva Who what first bought

"Who bought what first?"

b. *koj pruv kakvo kupuva

who first what bought

In (34a), no parenthesis should be used to separate the wh-word "koj" and the wh-word "kakvo". If "first" is inserted, the sentence (34b) is ungrammatical. This shows that in Bulgarian language, all wh-words moved to initial position of the sentence should be considered as one constituent (Ma, 2001; 2015; 2016a). A hypothesis can be made that in Bulgarian wh-questions, as the wh-feature in $\mathrm{C}$ is very strong, the verb should be moved out of the VP to C position, and all the wh-words are combined together as a whole according to superiority condition into one wh-operator and raised together to the front position of the sentence in order to check off the strong [+wh] feature of $\mathrm{C}$. this process is demonstrated in (35). In (35), C in wh-question carries a very strong [+wh] feature, and this feature attracts the wh-features of all the wh-words to move to Spec CP position in the front of the sentence for [+wh] feature checking. The wh-features of all the wh-words must be integrated into a wh-feature cluster. As the [+wh] feature in $\mathrm{C}$ is too strong, the morphological features of the wh-words also form a morphological feature cluster and piped-pipe with the [+wh] feature cluster. The $[+w h]$ feature in $C$ is in agreement with the [+wh] feature cluster of all the wh-words. As a result, (35) is interpreted as a wh-question. 
(35)

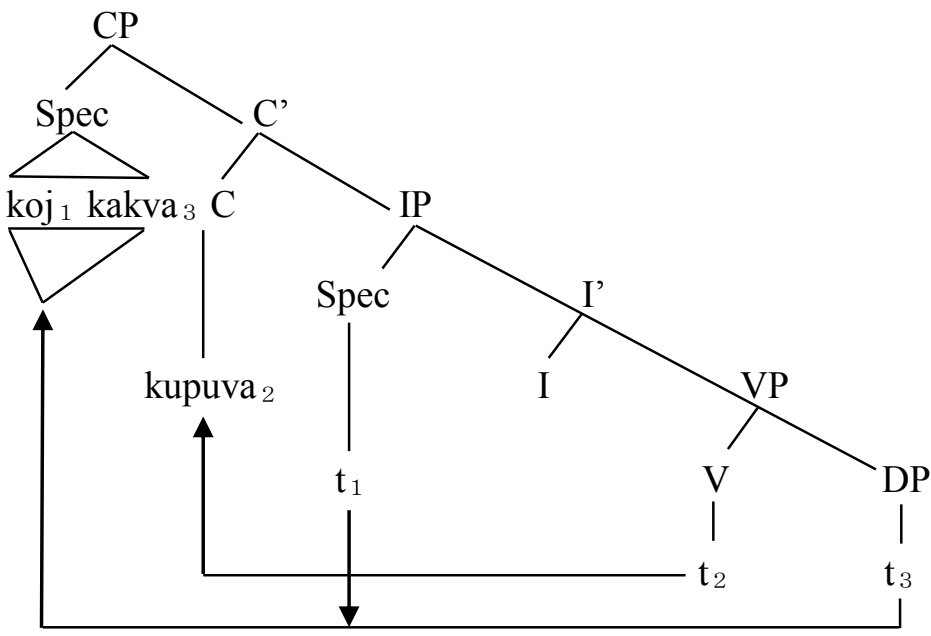

In (35), all the wh-words are formed into one question operator following superiority principle in Bulgarian and must be raised to the Spec position of $\mathrm{CP}$, and enter an operator variable binding relationship with its trace respectively. The wh-operator "koj" binds its trace " $\mathrm{t}_{1}$ " and the wh-operator "kakva" binds its trace " $\mathrm{t}_{3}$ ".

\subsection{Non-Multiply Filled Spec Language}

In Czech all the wh-words must move, but different from Multiply Filled Spec Languages, only one wh-word is raised to the Spec CP position in the initial position of the sentence. After the moved wh-element, no other wh-word should be allowed to follow it and there must be another syntactic constituent after it as in (36a). If two wh-wrods are moved into the front position of Spec CP as it is the case in Bulgarian, the sentence is ungrammatical as in (36b). In Czech, wh-wrods can be isolated by other constituent, which shows that in Czech the wh-words cannot be integrated into one operator (Ma, 2001; 2015; 2016a; 2018). In Czech language, the wh-feature of C is strong but not as strong as in Multiply Filled Spec Languages, because the wh-feature of C can only attract the $[+$ wh] feature of one wh-word to move to Spec CP position in the front of the sentence. If the $[+w h]$ features of the two wh-words form a feature cluster as it is in Bulgarian and the wh-words are attracted by the strong feature of $\mathrm{C}$ to pied-pipe to Spec $\mathrm{CP}$ position, the sentence turns to be ungrammatical as in (36b).

(36) a. kdo ho kde videl je nejasme who he where see is difficult-to-understand "I do not understand who saw him where?"

b. *kdo kde ho videl je nejasne who where he see is difficult-to-understand

When a wh-word is moved to Spec CP in Czech, it is allowed only to adjoin at most another wh-word to Spec CP position. Different from Multiply Filled Spec Languages, in Czech wh-movement to Spec CP in whquestions must not violate wh-island condition, and all the other wh-words must adjoin to IP as in (37). In Czech language, the wh-feature of $\mathrm{C}$ is strong and the wh-feature of $\mathrm{C}$ can only attract the $[+w h]$ feature of one whword pied-piped with the morphological feature of the wh-word to move to Spec CP position in the front of the sentence, the $[+w h]$ feature of $\mathrm{C}$ is checked and the sentence is interpreted as a wh-question. Besides, another wh-word can be adjoined to $\mathrm{C}$ and all the other wh-words must adjoin to IP. Apparently, these wh-words adjoin to IP not for checking of the [+wh] feature of $\mathrm{C}$ but to check the [+Foc] feature of focus in IP.

(37) a. kdo rychle co komu dal Who quickly what to whom give "Who give whom what quickly?"

b. kdo co rychle komu dal who what quickly to whom give "Who give whom what quickly?"

As is shown in (38), the order of wh-words in wh-questions in Czech is free, in which they are not restrained by 
superiority principle and economy principle.

(38) a. kdo, podle tebe, co komu dal who, you see, what to whom give

"As you see, who give whom what?"

b. kdo co, podle tebe, komu dal who what, you see, to whom give "As you see, who give whom what?"

If the parentheses "podle tebe" ("as you see" in English) can be neglected as it does not influence the syntactic structure of the sentence, the tree diagram of (38) is (39).

(39) a.

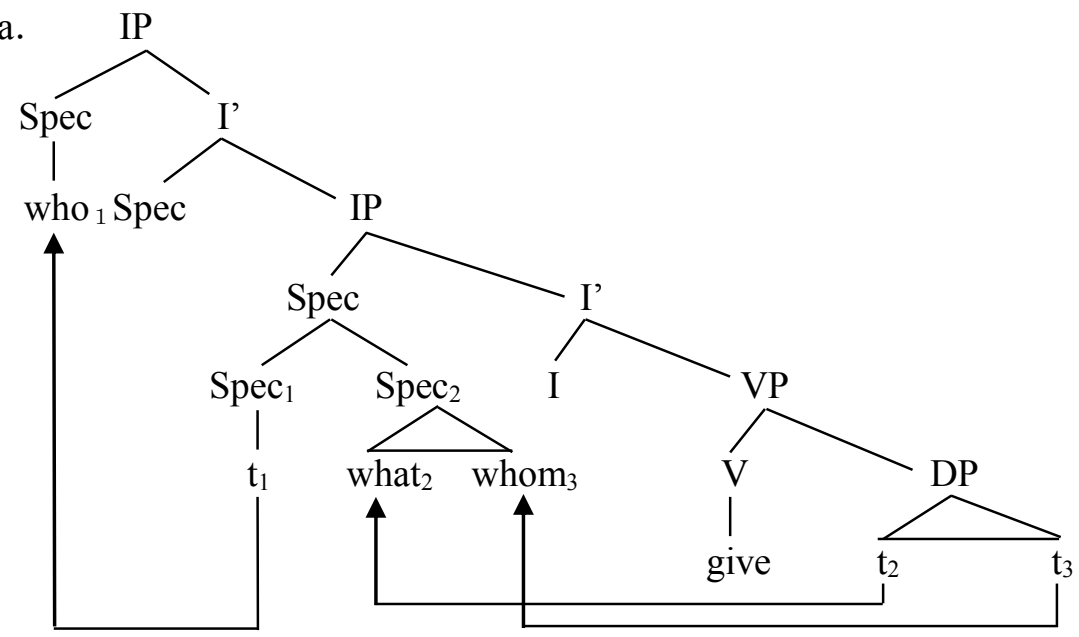

b.

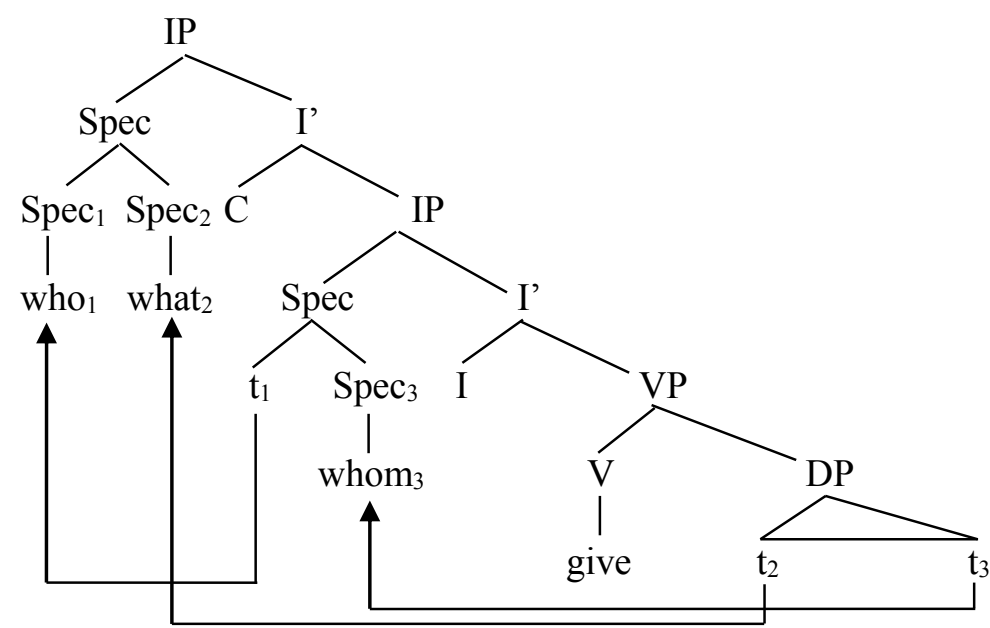

\section{Conclusion}

The study of the wh-feature checking of the wh-features in the wh-questions of the four types of natural languages reveals that Move $\mathrm{F}$ of feature movement is universal in feature checking. In the four types of natural languages, feature checking of the wh-feature of $\mathrm{C}$ follows the Wh-feature Attraction Principle: The wh-feature of a wh-word or a wh-phrase must be attracted to spec $\mathrm{CP}$ in wh-questions for wh-feature checking requirement. Move F is universal: In some languages such as in Chinese no pied-piping of the morphological features of the wh-words is needed while in other types of languages pied-piping of the morphological features of the whwords is required. In Single Filled Spec Languages such as in English, only the feature of one wh-word is attracted to the Spec CP position in the front of the wh-questions, and the morphological feature of the wh-word pied-pipe with the wh-feature so that only one wh-word is attracted to move to the initial position of the sentence. In Multiply Filled Spec Languages such as in Bulgarian, all the feature of the wh-words form a feature cluster 
and are attracted to the Spec CP position in the front of the wh-questions, and all the morphological features of the wh-words also form a morphological feature cluster and pied-pipe with the [+wh] feature cluster so that all the wh-words are raised to the front position of the sentences. In Non- Multiply Filled Spec Languages such as in Czech, only the feature of one wh-word is attracted to the Spec CP position in the front of the wh-questions, and the morphological feature of the wh-word pied-pipe with the wh-feature so that only one wh-word is attracted to move to the initial position of the sentence. Besides, another wh-word can be adjoined to $\mathrm{C}$ and all the other wh-words must adjoin to IP. Apparently, these wh-words adjoin to IP not for checking of the [+wh] feature of $\mathrm{C}$ but for checking the $[+\mathrm{Foc}]$ feature of focus in IP. The study thus proves that the Wh-feature Attraction Principle should be universal.

\section{References}

Ackema, P., \& Neeleman, A. (1998). Optimal Questions. Natural Language and Linguistic Theory(16), 443490.

Aoun, J., \& Li., Y.-H. A. (1993a). WH-elements in situ: Syntax or LF? Linguistic Theory (24).

Aoun, J., \& Li., Y.-H. A. (1993b). Syntax of Scope. Massachusetts: MIT Press.

Cheng, L. L.-S. (1997). On the Typology of Wh-questions. PHd dissertation, MIT.

Chomsky, N. (2008). The Minimalist Program. Cambridge: MIT Press.

Huang, J. C.-T. (1982a). Move WH in a language without WH-movement. The Linguistic Review(1), 369-416.

Huang, J. C.-T. (1982b). Logical Relations in Chinese and the Theory of Grammar. Doctoral Dissertation, MIT.

Kayne, R. (2015). The Silence of Heads. New York : New York University.

Ma, D. ( 2006a). On the Syntactic Proof of the Interrogative Particle "Ne". Journal of Chinese Linguistics(12), $100-112$.

Ma, D. (2000). A Generative Approach to Interrogative Sentences. MA Thesis, Shandong University.

Ma, D. (2001). The Types of Natural Languages from the Perspective of Generative Studies of Wh-questions. Contemporary Research in Modern Chinese(3), 23-37.

Ma, D. (2004a). The Syntactic Interrogativeness of the Particle "Ne". IACL-12 \& ISCL-2.

Ma, D. (2004b). Is the Mood Auxiliary "Ne" a Clause Typing Marker? Yellow Sea Academic Forum(4), 150156.

Ma, D. (2006b). Is the Question Particle "Ne" a Question Operator? Chinese Foreign Language(2), 43-47.

Ma, D. (2008). The Translation of Interrogative Sentences in Laozi and Its Typological Significance. Theoretical Linguistic Studies(2), 101-108.

Ma, D. (2014). A Syntactic Study of the Interrogative Sentences and Its Typological Significance in the Selected Readings from the Works of Mao Tsetung. Journal of Beijing International Studies University( 10), 14-23.

Ma, D. (2015). The Syntactic Studies of Interrogative Sentences in the West and Their Deficiencies. Guangzhou: World Book Publishing Co. Ltd.

Ma, D. (2016a). An Outline of English and Chinese Syntax. Guangzhou: World Book Publishing Co. Ltd.

Ma, D. (2016b). The Distribution and Feature Checking of Interrogative Sentences in Tao Te Ching. International Journal of Language and Linguistics , IV(6), 230-236.

Ma, D. (2017a). Feature Attraction of Wh-questions in the Bamboo Slips of Tao Te Ching. IMPACT: International Journal of Research in Humanities, Arts and Literature (IMPACT: IJRHAL), V(1), 3950 .

Ma, D. (2017b). Wh-Feature Attraction and Affix Particles in Tao Te Ching. Internationl Journal of Research in Social Sciences, VII(3), 678-695.

Ma, D. (2017c). Left Periphery and Feature Checking of Wh-questions in Tao Te Ching. BEST: International Journal of Humanities, Arts, Medicine and Sciences (BEST: IJHAMS), V(2), 133-144.

Ma, D. (2017d). Feature Checking of Wh-questionsin the Selected Readings from the Works of Mao Tsetung. International Research Journal of Humanities, Language and Literature., IV(2), 13-32.

Ma, D. (2018). Biologically Relevant Universality of Move F in Wh-questions. Open Access Library Journal, $V(3)$.

Rudin, C. (1988). On Multiple Questions and Multiple WH Fronting. Natural Language and Linguistic Theory(6), 445-502.

Shi, D. (1994). The Nature of Chinese Wh-questions. Natural Language and Linguistic Theory(12), 301-333. 
Tang, S.-W. (2015). A Generalized Syntactic Schema for Utterance Particles in Chinese. Lingua Sinica, I(3), $1-23$.

Tsai, W.-t. D. (1994). On Economizing the Theory of A-bar Dependencies. dissertation, MIT, MIT doctoral. $\mathrm{Wu}, \mathrm{J}$. (1999). Syntax and Semantics of Quantification in Chinese. PhD dissertation., University of Marylandat College Park. 